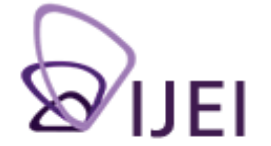

International

Journal for

Educational Integrity

\title{
Negotiating identity and integrity on social network sites for educators
}

\author{
Brady Robards \\ Griffith University \\ b.robards@griffith.edu.au
}

Keywords: audience segregation, identity, integrity, social network sites, youth.

\begin{abstract}
Discussion around the use of social network sites, especially amongst young people, is pervaded by sentiments heralding the decline of privacy. In this context, it is important for scholarship in this area to attend to the array of ways in which individuals are managing their information and identity-projects in these spaces in highly strategic ways, such as audience segregation. Drawing in part on empirical data collected through an ethnography of young Australian users of MySpace and Facebook, this article seeks to draw out the tension between authenticity and integrity that operates in these spaces. In doing so, I suggest that educators must be especially cognisant of the complexity occurring in the strategic management of these spaces, given the ongoing push for universities and agents within the university to engage with these spaces, along with the tension such engagement can bring to the teacher-student relationship.
\end{abstract}

\section{Introduction}

Mark Zuckerberg, the CEO and co-founder of Facebook and the recently announced Time magazine Person of the Year, has a very clear philosophy on identity and integrity in an era in which more than five hundred million people (Facebook 2010) or one-twelfth of humanity are using his service:

"You have one identity," [Zuckerberg] says emphatically three times in a single minute during a 2009 interview [...] "The days of you having a different image for your work friends or co-workers and for the other people you know are probably coming to an end pretty quickly," he says [...] "Having two identities for yourself is an example of a lack of integrity," [...] "the level of transparency the world has now won't support having two identities for a person" (Kirkpatrick 2010, p.198, italics added).

There are two key problematic dimensions to this claim. The first is the over-arching assumption about transparency and privacy. The second, which overlaps with the first, is Zuckerberg's insistence that multiplicity is synonymous with a lack of integrity. I will return to this argument in the second part of this article. Initially, however, by way of introduction, I will focus on the broad assumption in this quote about transparency and privacy. As is the case here, assertions about the rise of what we may refer to as the "information age" (Castells, 1996) or more recently (and perhaps hyperbolically) the "age of Facebook" (Raynes-Goldie, 2010) are often conflated with arguments about the decline of privacy. I would suggest that the decline of privacy and the emphasis on the "level of transparency the world has now" (Zuckerberg in

The International Journal for Educational Integrity is available online at:

http://www.ojs.unisa.edu.au/journals/index.php/IJEI/

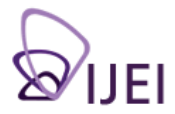


Kirkpatrick 2010, p.198) is overplayed, not only in Facebook's own rhetoric but also in broader discourses concerned with social network sites.

My arguments here are informed by a qualitative ethnography of 40 users of MySpace and Facebook aged $15-27$, conducted on the Gold Coast in two phases: the pilot phase was in 2008 with 10 MySpace users (before the rise in popularity of Facebook in Australia), with the formal phase being conducted in 2009/2010 with 30 Facebook and MySpace users. Data was collected through a series of in-depth, semi-structured interviews that were coupled with a discourse analysis of participants' profile pages. For a detailed discussion of the findings from this study, see Robards (2010; forthcoming 2011).

Contrary to Zuckerberg's philosophy, many of the young people in this study, with a variety of backgrounds and levels of education, are highly strategic in managing their privacy and information online. This level of strategic engagement with social network sites involves discretion in the sharing of information and a nuanced understanding of who their audience is. Problematically, social network sites such as MySpace and Facebook collapse the entire array of social relationships into just one category, that of 'Friend'. This creates an awkward social space for users, and this tension has given rise to an online version of what Goffman referred to as 'audience segregation [...] a device for protecting fostered impressions' (1959, p.57, italics added).

Users achieve audience segregation through various strategies. On Facebook, for example, Friends can be assigned to 'lists', allowing peers to be separated from family, and casual acquaintances distinguished from close friends. Segregation by this method subverts Facebook's transparency model which conflates these 'Friendship categories'. This strategy allows varying levels of content control to be exercised, such that one's work colleagues (or mother, as is often the case) can only access certain parts of a profile whereas close friends may be able to access the entire profile. Other methods of audience segregation include having multiple profiles on a single site (which Facebook's terms of service prohibit, presumably driven by Zuckerberg's transparency philosophy), or by maintaining profiles on multiple sites such as Facebook, MySpace, Twitter, Tumblr, Linkedln, Academia.edu, YouTube and so on, with each site serving as a performative platform for separate audiences. Different sites also carry with them clear differences in practice. As Huberman, Romero and Wu (2009) explain, one Twitter 'following' another user does not always ensure two-way interaction. It is possible to follow, but not be followed in turn, whereas many profile-based social network sites require the articulation to be twoway; you cannot be 'Friended' without in turn 'being a Friend'. The verb 'Friended' (as in to 'Friend') is used to describe the process of articulating a social tie between users on social network sites, which is consistent with boyd's use of the term (2007, p.134). The terminologies of these interactions are themselves problematic, and I will return to this issue in the final section of this article.

Even between similar sites such as MySpace and Facebook, there are differences in expected practice (Dwyer, Hiltz \& Passerini 2007). While my research has indicated that MySpace is more popular amongst younger users who primarily seek to engage exclusively with their peer group, Facebook appears to have a much broader appeal and its users therefore frequently engage with a broader audience. To negotiate their identity performances accordingly, the individual often employs the aforementioned strategies of audience segregation (Robards, 2010). Thus, while on one hand Facebook attempts to collapse these relationships into a single space, users, having negotiated the tensions inherent in constructing a sense of self in online social spaces, are on the other hand reversing that conflation through strategies of audience segregation.

The second problematic dimension arising from the opening quote from Zuckerberg, introduced earlier as overlapping with the first dimension and yet nonetheless worth 
separating, is the singular model of identity that Zuckerberg advances. In many ways, his claim that multiplicity implies a lack of integrity is reminiscent of early moral panics around online identity, best articulated by Turkle (1995) through the work of Rheingold (1994) and Gergen (1991): "Multiplicity is not acceptable if it means being confused to a point of immobility", Turkle (1995, p.257) warns. While along with Rheingold and Gergen, Turkle goes on to offer an optimistic narrative about identity on the internet from their positions in the early 90 s, the threat of multiplicity (and the attendant risk of losing a sense of identity cohesion) clearly persists in current and very powerful discourses about how individuals engage with the construction and formation of identity in online social spaces. The value of these spaces to operate as both archives of and tools in the "reflexive project of the self" (Giddens 1991) is constantly underplayed in a context where narratives concerned with the negative implications of these sites prevail.

How is this relevant for educators and those concerned with educational integrity? As adoption of social network sites continues and as educators and students engage with each other and their schools and universities through new channels such as Facebook and Twitter - a use that is increasingly encouraged or mandated by the educational institutions themselves - questions about professional identity and managing relationships with students must be renewed and revisited. As Goffman (1959) explained, the image of the professional is performed and maintained through a careful process of impression management. In contexts where multiple relationships are conflated, how does the individual maintain a coherent and authentic narrative of self? I would argue that integrity, in this context, is necessarily bound to questions of authenticity and coherence.

As the young people in my study demonstrated through their often complex audience segregation strategies, negotiating the identity of friend, son or daughter, co-worker, lover and perhaps future employee (amongst other combinations) in a single performative space is a difficult proposition. Adding the identity of student or teacher to this often competing set of performances provides yet another layer of complexity. If the student presents himself as serious about his education because of the presence of an imagined audience, which may include his instructor, how might this performance be read by his peers with whom he often shares stories of night-before essays or last-minute exam cramming? Amongst students (and colleagues) how might the lecturer negotiate her identity as committed teacher when her friends tag pictures of her enjoying a few drinks, or when her relationship status changes from 'married' to 'single' (or vice-versa)? These are performances usually mediated by physical space and long-standing social conventions. Online, in a space where the performance of identity is articulated, carefully managed and subsequently archived, can these multiple positions co-exist authentically and coherently whilst maintaining a sense of integrity?

This line of questioning highlights a tension in these spaces between integrity and authenticity. It is a tension that all users of any social network site must negotiate at some point. As the negative representations of social network sites in popular discourse remind us, some individuals appear to do so more successfully than others. As Gillespie (2002) suggests, there are competing narratives about the extent to which egalitarian relationships between students and teachers should be fostered. How might a teacher manage a Friend request from a student? Clearly, this will depend on the context. It may be more appropriate for a doctoral candidate and supervisor to be friends (and Friends) than it is for a high school teacher and student, as questions of agency, power relationships and the ethics of the teacher-student relationship come into play. The problem with the terminology here is that Friendship on Facebook, for example, is distinct and in many ways diluted from its traditional usage. It is possible, as my own research (and practice) has demonstrated, to be a Friend without being a friend. What is central, however, for any agent engaging with social network sites - whether at the institutional level for policy makers and 
administrators or at the level of the student and teacher - is recognition of the complexity of these spaces. Most individuals have pre-existing strategies for managing their performances, and these strategies do not always align. Requiring or encouraging students to engage with a social network site (that they may frame as private or for a particular audience) for the purposes of assessment or to facilitate communication can be highly problematic. Similarly, the educator must make informed and strategic decisions about how to respond to unsolicited contact from their students (and perhaps colleagues and the wider community) that takes the complexities and nuances of these spaces, as outlined here, into consideration.

In summary, in this short invited contribution I have attempted to frame a discussion of the performance of identity on social network sites (such as MySpace and Facebook) through a focus on questions of integrity for educators. While Mark Zuckerberg insists that we are living in a world where privacy is dead and open transparency is the future, the questions raised throughout this article must be addressed. It is my contention that multiplicity can be managed coherently in these spaces while retaining a strong sense of integrity. However, as with social interactions in physical spaces, this is no easy task and can only occur effectively after a certain level of reflexive and strategic thinking. Whether they frame their practice in these terms or not, young people (although certainly not exclusively young people) who have built an engagement with online sociality into their everyday lives, have learnt many of these strategies already. For individuals new to these spaces, or for individuals who are hesitant or concerned about these spaces, young people have many lessons to teach.

\section{About the author}

Brady Robards is an Associate Lecturer and PhD Candidate at Griffith University on the Gold Coast. Brady's research explores how young people use online social spaces (specifically social network sites such as MySpace and Facebook) to construct a reflexive sense of identity. The project is also concerned with how that sense of self is positioned within, across or in-between systems of belonging and how these systems of belonging (and the way scholars conceptualise them) are changing. Brady is a member of both the Australian Sociological Association (TASA) and the Cultural Studies Association of Australasia (CSAA).

\section{References}

boyd, d. (2007). 'None of this is real: Identity and participation in Friendster', in Karaganis J. (ed.) Structures of Participation in Digital Culture, Social Sciences Research Council, New York, 132 - 157.

Castells, M. (1996). The Information Age: Economy, Society and Culture, vol. 1, Blackwell, Oxford.

Dwyer, C., Hiltz, S.R. \& Passerini, K. (2007) 'Trust and privacy concern within social networking sites: A comparison of Facebook and MySpace', Proceedings of the Thirteenth Americas Conference on Information Systems, Keystone, Colorado August $09-12,2007$.

Facebook.com (2010). 'Facebook press room', accessed 23 September http:// www.facebook.com/press/info.php?statistics.

Gergen, K. (1991). The Saturated Self: Dilemmas of Identity in Contemporary Life, Basic Books, New York.

Giddens, A. (1991). Modernity and Self-Identity: Self and Society in the Late Modern Age, Stanford University Press, Stanford.

Gillespie, M. (2002). 'Student-teacher connection in clinical nursing education', Issues and Innovations in Nursing Education, 37(6), 566-576.

Goffman, E. (1959). The Presentation of Self in Everyday Life, Penguin, London. 
Huberman, B. A., Romero, D.M. \& Wu F. (2009) Social networks that matter: Twitter under the microscope, First Monday, 14(1), accessed December 14, 2010: http://firstmonday.org/htbin/cgiwrap/bin/ojs/index.php/fm/article/view/2317/2063

Kirkpatrick, D. (2010) The Facebook Effect: The Inside Story of the Company That is Connecting the World, Simon \& Schuster, New York.

Raynes-Goldie, K. (2010). Aliases, creeping and wall cleaning: Understanding privacy in the age of Facebook, First Monday, 15(1), accessed January 6, 2010: http:// firstmonday.org/htbin/cgiwrap/bin/ojs/index.php/fm/article/view/2775

Rheingold, H. (1994). The Virtual Community: Surfing the Internet, Minerva, London.

Robards, B. (2010). Randoms in my bedroom: Negotiating privacy and unsolicited contact on social network sites, PRism, (7)3, accessed June 3, 2010: http:// www.prismjournal.org/fileadmin/Social_media/Robards.pdf

Robards, B. \& Bennett, A. (2011 forthcoming) MyTribe: Postsubcultural manifestations of belonging on social network sites, Sociology, 45(2).

Turkle, S. (1995) Life on the Screen: Identity in the Age of the Internet, Touchstone, New York. 